\title{
In Loop Design of the Coils and the Electromagnetic Shielding Elements for the Wireless Charging Systems
}

\author{
Michal Frivaldsky * and Miroslav Pavelek \\ Department of Mechatronics and Electronics, Faculty of Electrical Engineering and Information Technologies, \\ University of Zilina, 01026 Zilina, Slovakia; miroslav.pavelek@feit.uniza.sk \\ * Correspondence: michal.frivaldsky@feit.uniza.sk
}

Received: 13 November 2020; Accepted: 14 December 2020; Published: 17 December 2020

\begin{abstract}
This paper deals with in loop design of coupling elements of the wireless charging systems (WChS). The in-loop design is created as a script/User Interface (UI) in MATLAB environment, which is based on finite element models of WChS. Main aim of developed tool is to easily identify the optimal geometrical parameters of the coupling coils. The optimization of the coil's geometrical and electrical parameters is specified by an algorithm, which is based on definition for transfer of required amount of power and on geometrical restrictions of the target application. The second part of the proposed script/UI is used for user guided design of the electromagnetic shielding. It enables to optimize the shielding parameters in order to reach the limits defined by international standards for safety levels with respect to human exposure. Proposed design methodology together with user interface have been verified though experimental validation. For this purpose, construction of WChS was realized based on the results from in loop design process. Comparisons have been made according to the evaluation of simulation model's accuracy, that is, the values of self-inductances, mutual inductances, coupling coefficient and gain characteristics have been evaluated (simulations vs. experiments). At the end of the paper the evaluation of the shielding performance was realized, while once more the comparison between simulation and experiments have been made. Received results are showing less than $2 \%$ of the relative error. Using presented methodology, the fast optimization actions can be done during design and modelling of WChS.
\end{abstract}

Keywords: wireless coil design; simulation; finite element method; accuracy; computer modelling; verification

\section{Introduction}

In addition to the regulations on wireless charging and its commercialization, it is necessary to consider several other important technical issues in the design of the system. Key factors of power electronic systems like energy efficiency and power density are leading to continual increase and have positive environmental, as well as economic impact. In connection to these facts, also the wireless power transfer (WPT) systems will face contradictory requirements imposed on their system components. Here we are talking about power electronic circuitry, coupling elements, compensation capacitors and thermal management, as well as EM (electro-magnetic) shielding system. The regulations of the power semiconductor systems determined by international organizations like, U.S Energy Star, 80 Plus, Climate Savers, German Blue Angel and so forth are completely different from the regulations defined for the WPT operation. It is therefore a complex task to design high-performance WPT system that will comply with all technical and safety regulations at once. Currently there are various studies describing design procedures of WPT coupling coil system [1-5], studies related to control strategies 
for power delivery regulation [6-8] and many studies related to power electronic system analysis and evaluation of the operational properties [9-13]. Many of them are focusing on the evaluation of the qualitative indicators of WPT systems, whose are efficiency and power density at all but also the amount of delivered power in dependency on distance of the transferred power. When talking about battery charging in automotive industry, then the series-series compensation topology is the best choice [14-16]. Typical equivalent circuit of this topology is being shown on Figure 1, while secondary side is replaced by equivalent load, which considers the effect of secondary AC/DC converter together with battery charging module. As we focus more deeply on this topology, here it must be noticed that commercial use is also an alternative, while biocompatibility is very important issue. Here we are talking about safety standards [17-19], which are defining limits for the safe interaction between EM field and living organisms. The ways for keeping safety limits within definitions are based on the EM shielding. The literature proposes several analyses focused on this topic but only a few of them are supported with the leakage fields' measurement.

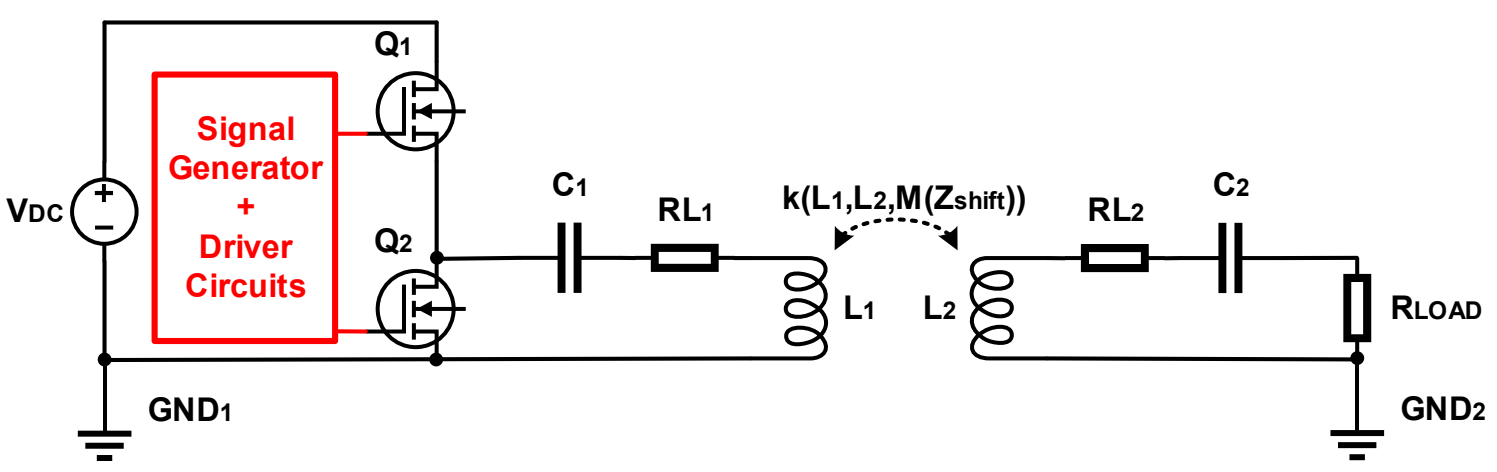

Figure 1. Basic electric scheme of wireless charging systems (WChS) with serial-serial resonant compensation end equivalent secondary DC load resistance.

Considering previous facts, proper design of any WPT charging system represents complex and hard task in order to be successful with the design. If we consider that currently manufacturers of power electronic components offer circuit simulators enabling to provide highly accurate circuit simulations, the point is that there is still lack of simulation tools, which could simplify design procedure of WPT system. Power converters are currently available in the form of complete modules practically suitable for wide application spectrum. The coupling coil system therefore represents very important system component, which requires increased attention considering optimized design. For this purpose, an automated in-loop design procedure is beneficial, while it considers most important issues of the coil system design together with the possibility of optimization of system parameters like efficiency, EM performance, efficiency and so forth. Given approach can be realized using simulation tool. Therefore, this article describes the design and development of simulation model of the WPT system, verified by experimental measurements. As was mentioned, considering automotive industry, the series-series compensation topology (Figure 1) is proper choice for charging, therefore design process considerers given topology. Proposed model can provide precise information related to magnetic fields distribution (electric and magnetic intensities related to regulations), faster and more accurate determination of operation conditions (i.e., efficiency, peak power, transfer distance, component stresses). The advantages of proposed procedure are related to the high validity results for direct WPT system development enabling further optimization of the mentioned systems.

2. Description of Geometry Calculations of Coupling Elements of Wireless Charging System and Its FEM (Finite Element Method) Model

The simplified model of coupling coils of WChS was developed in COMSOL environment using combination of two physic interfaces: 
- $\quad$ Magnetic fields (mf)

- Electrical circuit (ec)

The model is created as an 2D axisymmetric model within air environment. This approach simplifies markedly final model generation and optimizes computation time required for identification of the electromagnetic fields. For the coils themselves and shielding system, the geometry of rectangle blocks is being used (Figure 2).

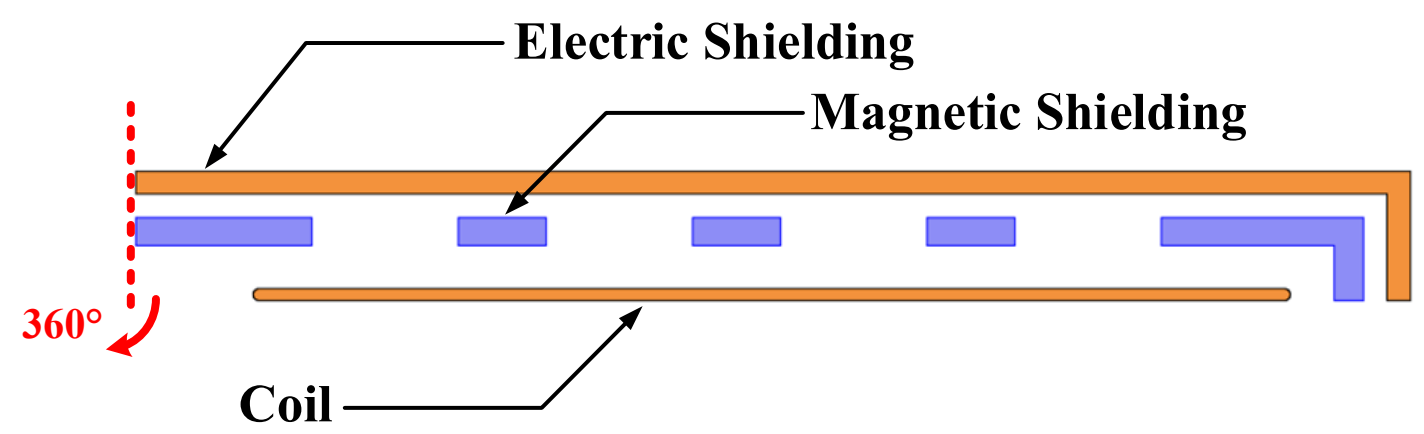

Figure 2. Simplified model of coil for WChS.

The mentioned model (Figure 2) is fully reconfigurable in following ways:

- Coil Geometry/Material Parameters

- Application of Magnetic shielding/Geometry/Material Parameters

- Application of Electric shielding/Geometry/Material Parameters

- $\quad$ System parameters (Power Transfer Distance)

The model itself is divided to four sub models, which are used for wireless charging system optimization. The first two models are used to determine values of primary and secondary coil inductance and the value of parasitic resistances. The third model is used to determine mutual inductance of non-compensated WChS (without resonant capacitors added within the circuit). The fourth model is used to identify the shape of the transfer characteristics and to calculate the electromagnetic field radiation of designed system of coupling elements, while these main results are valid under consideration of series-resonant compensation of the WChS.

(a) Calculation of coil's geometrical properties considering WChS efficiency requirements

The procedure of the calculation of basic geometrical parameters is discussed here. The first input parameter is radius of the coil's wire $R_{W}$. Its value is in relationship to required efficiency of wireless power transfer $\eta$, expected nominal load $R_{L O A D}$, the value of transferred power $P_{O U T}$, recommended current density $J\left(3 \mathrm{~A} / \mathrm{mm}^{2}\right)$ [1] and the number of parallel wires $N_{W}$ as follows (1):

$$
R_{W}=\sqrt{\frac{P_{\text {OUT }}}{\sqrt{P_{\text {OUT }} \times R_{\text {LOAD }}} \times \eta \times J \times N_{W}}}
$$

Here it is required to define the minimal required value of the input DC voltage, while it is defined by next Equation (2):

$$
V_{I N}=\sqrt{P_{\text {OUT }} \times R_{L O A D}}
$$

Consequently, from the value of specific resistance of the wire $\rho$ (copper material), from value of operating frequency $f$ and from the value of magnetic permeability $\mu$ it is possible to determine the skin depth using (3):

$$
\delta=\sqrt{\frac{\rho}{f \times \pi \times \mu}}
$$


where $f$ is the operational frequency and $\mu$ is the permeability. Using (3) and (1), the value of maximal radius of the wire $\left(R_{W}\right)$ can be determined (4). Because skin depth is considered here and to avoid "skineffect," litz wire shall be used, while the number of the wires is defined using (5):

$$
\begin{gathered}
R_{L W}=\delta \\
N_{L W}=\frac{R_{W}^{2}}{R_{L W}^{2}},
\end{gathered}
$$

where $R_{L W}$ is radius of one wire of litz wire, $N_{L W}$ is number of wires used to design litz wire. Using the value of nominal load of the system and considering efficiency of the power transfer it is possible to determine maximal admissible parasitic resistance of the coil $\left(R_{\text {coil }}\right)(6)$

$$
R_{\text {coil }}=\frac{\frac{R_{L O A D}}{\eta}-R_{L O A D}}{2}
$$

The important parameter, which influences the value of parasitic capacitance of the coil $\left(C_{\text {coil }}\right)$ is radial displacement of individual turns. To reach minimal value of $C_{\text {coil }}(7)$ is being used for determination of the value of radial displacement $C_{R A D}$.

$$
C_{R A D}=5 \times R_{W}
$$

Considering specific value of the resistance of used wire and considering estimated value of parasitic resistance of the coil, it is desirable to calculate total length $\left(l_{\text {coil }}\right)$ of the coil's wire using $(8)$.

$$
l_{\text {coil }}=\frac{R_{\text {coil }} \times \pi \times N_{W} \times R_{W}^{2}}{\rho}
$$

Using (8) together with (7) and applying requirement on the outer diameter of designed coil it is possible to determine the number of coil turns (10) and its inner diameter (11).

$$
\begin{gathered}
l_{\text {coil_ } i}=l_{\text {coil_ } i}+\pi \times\left(D_{\text {out }}-2 \times C_{R A D} \times\left(N_{i}-1\right)\right) \\
N=N_{i} ; i\left(l_{\text {coil_ } i} \geq l_{\text {coil }}\right) \\
D_{\text {in }}=D_{\text {out }}-2 \times C_{R A D} \times\left(N_{i}-1\right),
\end{gathered}
$$

where $D_{\text {out }}$ is coil's outer diameter, $N_{i}$ is $i$-th number of coil's turn, $N$ is the number of turns, $D_{i n}$ is inner diameter of the coil.

The conditions listed above (9)-(11) determines, that the calculation of the coil's geometry is optimized to reach defined requirements on the efficiency and on the amount of the transferred power.

(b) Physical boundary and subdomain settings of the FEM model

The previous mathematical model is used for determination of the coil geometry, while the FEM model is using following physical and domain settings (Table 1) for its individual parts.

Standard equations for modelling of magnetic fields are being used within model (12)-(14):

$$
\begin{gathered}
\nabla \times H=J \\
B=\nabla \times A \\
J=\sigma E+\sigma v \times B+J_{e}
\end{gathered}
$$

where " $H$ " is Magnetic Field Density, " $J$ " is Current Density, " $B$ " is Magnetic Flux Density, " $A$ " is Magnetic Vector Potential, " $E$ " is Electric Field Intensity, " $\sigma$ " is Electrical Conductivity, " $v$ " is Velocity of moving geometry and " $J e$ " is Externally Generated Current. 
For the domain defined by the "Ampère's Law" condition the Equations (12) and (13) are used while the Equation (14) is used in simplified form (15). For the calculation of electrical intensity Equation (16) is being used.

$$
\begin{gathered}
J=\sigma E+j \omega D \\
E=-j \omega A
\end{gathered}
$$

where " $D$ " is Electric Flux Density and " $\omega$ " is Angular Frequency.

The current density in the Coil's domains is calculated based on the equation (17).

$$
J_{e}=\frac{N I_{\text {cir }}}{A}
$$

where " $N$ " is Number of turns and " $I_{c i r}$ " is Total Current.

Above mentioned equations are representing basic set of mathematical expressions, which are

\begin{tabular}{|c|c|c|c|c|c|}
\hline Settings $\quad$ Domain & Environment & Coil 1 & Coil 2 & $\begin{array}{l}\text { Magnetic } \\
\text { Shielding }\end{array}$ & $\begin{array}{c}\text { Electric } \\
\text { Shielding }\end{array}$ \\
\hline Material & Air & Copper & Copper & Ferrite "N92" & Copper \\
\hline Ampère's Law & Yes & No & No & Yes & Yes \\
\hline $\begin{array}{l}\text { Magnetic Field Component } \\
\text { (Coil 1) }\end{array}$ & No & Yes & No & No & No \\
\hline $\begin{array}{l}\text { Magnetic Field Component } \\
\text { (Coil 2) }\end{array}$ & No & No & Yes & No & No \\
\hline $\begin{array}{l}\text { Electrical Circuit Component } \\
\qquad\left(\mathrm{I}_{\mathrm{L} 1} \text { to } \mathrm{V}_{\mathrm{L} 1}\right)\end{array}$ & No & Yes & No & No & No \\
\hline $\begin{array}{l}\text { Electrical Circuit Component } \\
\qquad\left(\mathrm{I}_{\mathrm{L} 1} \text { to } \mathrm{V}_{\mathrm{L} 1}\right)\end{array}$ & No & No & Yes & No & No \\
\hline
\end{tabular}
being used within proposed modelling approach.

Table 1. Domains settings and boundary conditions definition.

\section{Basic Definitions for the in-Loop Coil Design and Its Validation}

It was already discussed, that developed model uses four calculation stages for identification of the operational properties of WChS. These stages can be divided within several steps:

- Self-inductance and parasitic resistance determination of a Non-Shielded Coil

- Self-inductance and parasitic resistance determination of a Coil with magnetic shielding

- Mutual inductance determination of non-compensated WPT system with Non-Shielded Coils

- $\quad$ Transfer Characteristic identification of compensated WPT system-without shielding

- $\quad$ Transfer Characteristic identification of compensated WPT system-with magnetic shielding

- Electromagnetic radiation identification of WPT system in given distance (shielded/non-shielded)

Because the FEM model is integrated within in the loop procedure utilizing script/UI in MATLAB, the definition of the relationship of geometry parameters is required (18)-(20). In this way proposed model flexibly enables to identify main coils parameters that is, self-inductances and parasitic resistances.

$$
\begin{gathered}
w=2 \times N \times R_{W}+(N-1) \times C_{R A D} \\
h=2 \times R_{W} \\
x=\frac{D_{i n}}{2},
\end{gathered}
$$

where " $w$ " is a COMSOL parameter defining width of rectangle, " $h$ " is a COMSOL parameter defining the height of the rectangle, " $x$ " is a COMSOL parameter defining the distance of the rectangle from the 
revolution axis, " $N$ " is number of coil's turns, " $R_{W}$ " is wire radius, " $C_{R A D}$ " is radial distance between turns of the coil and " $D_{\text {in }}$ " is internal diameter of the coil.

Second stage is based on the mutual inductance determination; thus, it is also important to define relationship within mutual position (mutual distance, misalignment etc.) of the system of coils. The coils itself are defined by Equations (18)-(20) with one difference for secondary coil, which defines the transfer distance of the WChS (21).

$$
y=Z_{\text {Shift }}
$$

where " $y$ " is a COMSOL parameter defining the distance from horizontal axis and " $Z_{\text {shift }}$ " is distance between the coils.

The value of mutual inductance is consequently determined using (22).

$$
M=\left|\frac{m_{f} \cdot V_{\text {Coil_2 }}}{m_{f} \cdot I_{\text {Coil_1 } 1} \times m_{f} . \text { omega }}\right|,
$$

where " $m_{f} . V_{\text {Coil }} 2$ " is the inducted voltage on secondary the secondary coil, " $m_{f} . I_{\text {Coil__ }}$ " is current at the primary coil and " $m_{f}$.omega" is angular frequency.

The accuracy of FEM model and in loop design procedure were verified by comparing the characteristics of the relevant coupling coil system suited for practical experimentations of WChS (Figure 3). This system is composed of two coils located within frame that allows reconfiguration of the transfer distance of the system. The transfer distance is adjustable thanks to the guide lanes in corners of the frame and the helix in its center. Upper coil (secondary side) is static and the lower coil (primary side) is adjustable. The distance range is form $5 \mathrm{~cm}$ to $21 \mathrm{~cm}$. In this way, it is possible to identify transfer characteristic of WChS very precisely as motion step is app. $2 \mathrm{~mm}$ and influence from holding frame is neglected due to use of ABS material. Here it must be noticed that practical design of coupling coils was subjected to the calculation procedure defined by (1)-(11).

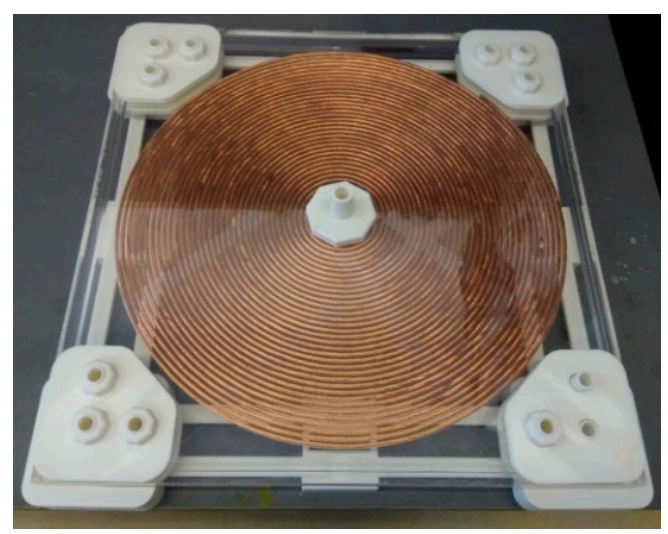

(a)

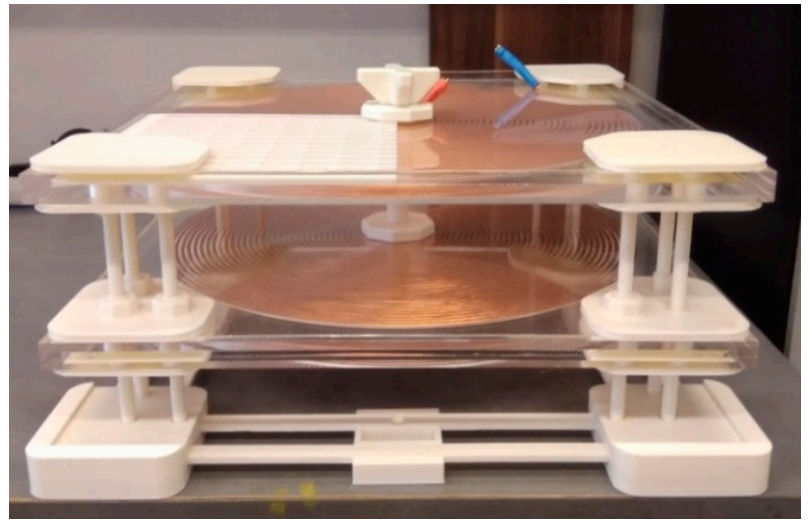

(b)

Figure 3. Coil's winding located within plexiglass matrices (a) and system of coupling coils of proposed wireless charging system with adjustable transfer distance $(\mathbf{b})$.

The first results of model verification are seen in Table 1, where the accuracy of the model for determination of the coil's self-inductance is higher than $98 \%$. The measurements have been realized with the use of high-precision LCR meter BK precision 891, whose measuring range is within $20 \mathrm{~Hz}-300 \mathrm{kHz}$ and max. 1\% error for selected operational range. Higher relative error (using Equation (23)) is seen for the case of parasitic resistance of the coil, while for primary and secondary side it achieves approximately $7 \%$. These results are valid for non-shielded system. The Table 2 also consists the geometrical parameters of the coupling coils. 


$$
\text { Error }=\frac{\text { Model }- \text { Meassurement }}{\text { Measurement }} \times 100
$$

Table 2. Geometry parameters of Non-Shielded Coils for model verification.

\begin{tabular}{|c|c|c|c|c|c|}
\hline & Turns " $\mathrm{N}_{\mathrm{i}}{ }^{\prime \prime}$ & $\begin{array}{l}\text { Inner Diameter } \\
\text { "Din }{ }_{\mathrm{i}}[\mathrm{mm}] "\end{array}$ & $\begin{array}{l}\text { Wire Radius } \\
\text { "r } \mathrm{r}_{\mathrm{i}}[\mathrm{mm}] "\end{array}$ & $\begin{array}{l}\text { Wire Gap } \\
\text { " } \mathrm{a}_{\mathrm{i}}[\mathrm{mm}] "\end{array}$ & \\
\hline Measurement & 36 & 40 & 1 & 5 & \\
\hline Model & 36 & 40 & 1 & 5 & \\
\hline Parameter & $\mathrm{f}[\mathrm{kHz}]$ & $\mathrm{L}_{1}[\mu \mathrm{H}]$ & $\mathrm{R}_{\mathrm{L} 1}[\Omega]$ & $\mathrm{L}_{2}[\mu \mathrm{H}]$ & $\mathrm{R}_{\mathrm{L} 2}[\Omega]$ \\
\hline Measurement & 85.5 & 217.1 & 0.267 & 217.5 & 0.265 \\
\hline Model & 85.5 & 221.2 & 0.246 & 221.2 & 0.246 \\
\hline Error [\%] & - & +1.89 & -7.9 & +1.7 & -7.2 \\
\hline
\end{tabular}

Because modelling procedure offers implementation of the electromagnetic shielding, similar verification listed in Table 1 was performed for fully shielded system, that is, both primary and secondary side uses configuration of shielding shown on Figure $4 \mathrm{a}$. At this point it must be discussed, that proposed in loop design offers possibility of the shielding reconfiguration according to example shown on Figure 3b. For the proper shielding technic, the magnetic material needs to have the highest possible magnetic permeability ( $\mu>800$ [-]-Powder Ferrite Cores) while the electrical conductivity needs to be as small as possible ( $\sigma<1[\mathrm{~S} / \mathrm{m}]$ _Powder Ferrite Cores). The electric shielding on the other hand must be designed from material with high electrical conductivity $\left(\sigma>6 \times 10^{7}[\mathrm{~S} / \mathrm{m}]\right.$-Copper). The two alternatives of magnetic shielding are seen at Figures $3 \mathrm{a}$ and $4 \mathrm{~b}$ respectively. The magnetic shielding is built from ferrite cores "N92" with dimensions $25 \mathrm{~mm}$ by $14 \mathrm{~mm}$ by $2.5 \mathrm{~mm}$. The frame for the shielding is 3D printed from "PLA" so there is no interference with the transfer properties of the WPT system.

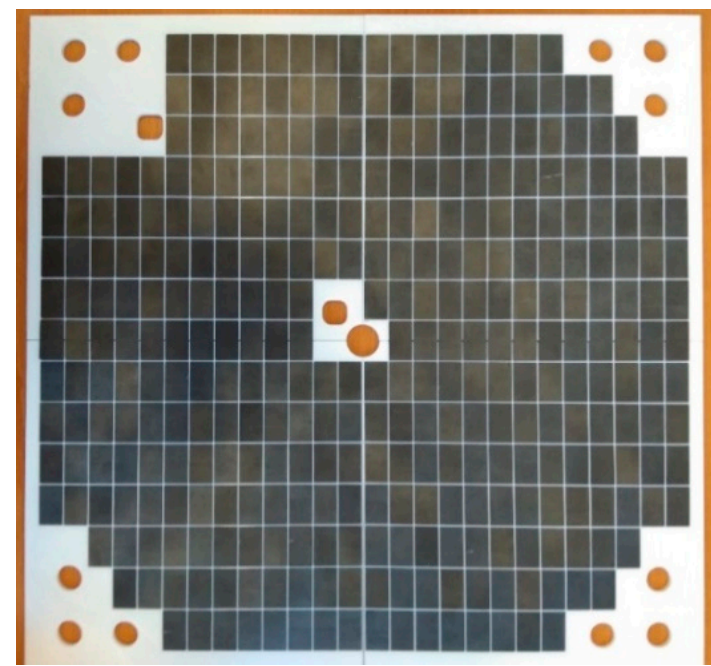

(a)

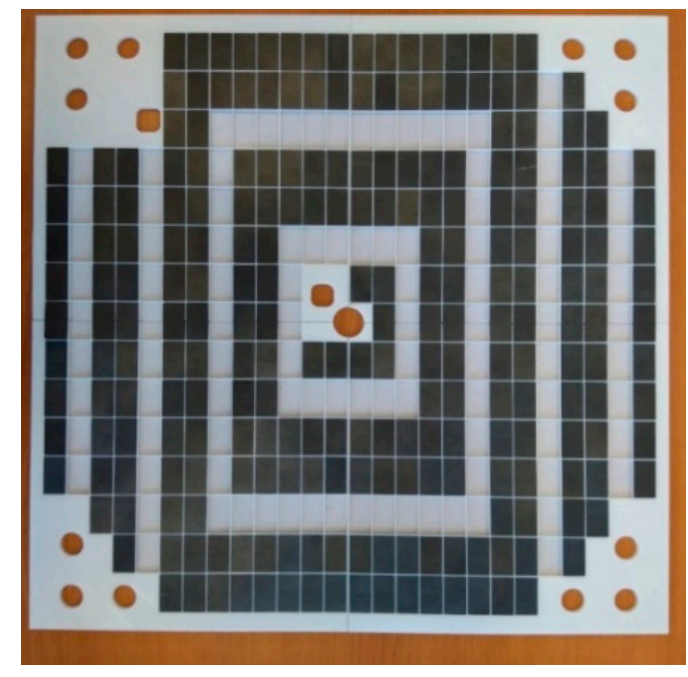

(b)

Figure 4. Practical alternatives of reconfigurable magnetic shielding (built form N92 Ferrite $-25 \times 14 \times$ $2.5[\mathrm{~mm}])$. (a) full system shielding, (b) partial system shielding (rings).

Verifications of the model accuracy have been done similarly to non-shielded system, so the measurements of the inductances and parasitic resistances are evaluated (Table 3). Once again LCR BK $891 \mathrm{~m}$ was used. As for previous case, the accuracy of the model for determination of the coil's self-inductance is higher than $98 \%$, while relative error for parasitic resistance reached approximately $7 \%$. 
Table 3. Geometry parameters of Shielded Coils for model verification.

\begin{tabular}{|c|c|c|c|c|c|}
\hline & $\begin{array}{l}\text { Turns } \\
\text { "Ni } \mathrm{N}_{\mathrm{i}}\end{array}$ & $\begin{array}{l}\text { Inner Diameter } \\
\text { "Din } \\
\text { [mm]" }\end{array}$ & $\begin{array}{l}\text { Wire Radius } \\
\text { "r } \mathrm{r}_{\mathrm{i}}[\mathrm{mm}] "\end{array}$ & $\begin{array}{l}\text { Wire Gap } \\
\text { " } \mathrm{a}_{\mathrm{i}}[\mathrm{mm}] \text { " }\end{array}$ & \\
\hline Measurement & 36 & 40 & 1 & 5 & - \\
\hline Model & 36 & 40 & 1 & 5 & - \\
\hline Parameter & $\mathrm{f}[\mathrm{kHz}]$ & $\mathrm{L}_{1}[\mu \mathrm{H}]$ & $\mathrm{R}_{\mathrm{L} 1}[\Omega]$ & $\mathrm{L}_{2}[\mu \mathrm{H}]$ & $\mathrm{R}_{\mathrm{L} 2}[\Omega]$ \\
\hline Measurement & 75.5 & 277.7 & 0.267 & 277.4 & 0.267 \\
\hline Model & 75.5 & 282.4 & 0.246 & 281.9 & 0.248 \\
\hline Error [\%] & - & +1.69 & -7.9 & +1.55 & -7.2 \\
\hline
\end{tabular}

The evaluation of the relative error was performed similarly to evaluation of relative error of the self-inductance. However, for this situation, the value of the error of mutual inductance was evaluated within whole range of expected transferring distance. Almost for this variable the accuracy was more than $98 \%$ within investigated transferring range $(60 \mathrm{~mm}-250 \mathrm{~mm})$.

For the third part of verification of the coil system from Figure 3 the value of the mutual inductance of the system was determined (coupling coefficient). The results from experimental measurement and simulation are compared and shown in Figure 5.

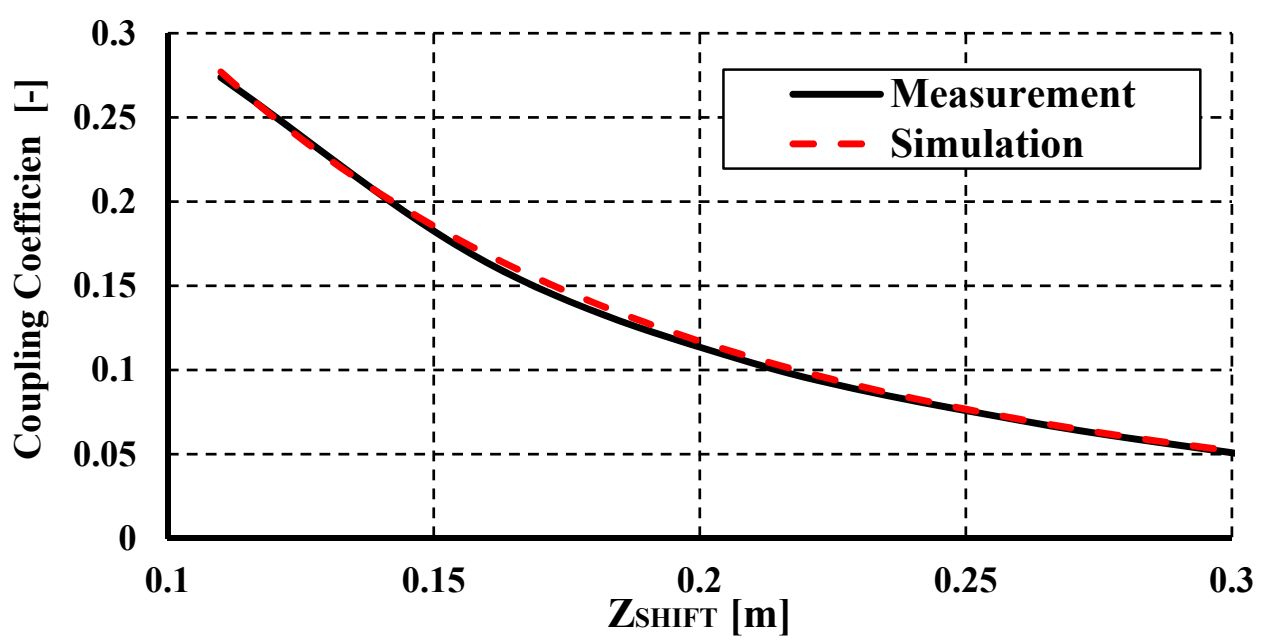

Figure 5. Model verification-Coupling coefficient dependency on transfer distance.

Fourth part of the model verification was focused on the investigation of the transfer characteristic of proposed WChS. Evaluated variable for this case is the value of transferred power in dependency on operating frequency, while both non-shielded system and system with magnetic shielding are analyzed. The model is supplemented by electrical circuit physics. The settings of the added physics can be seen in Table 4 (Figure 6).

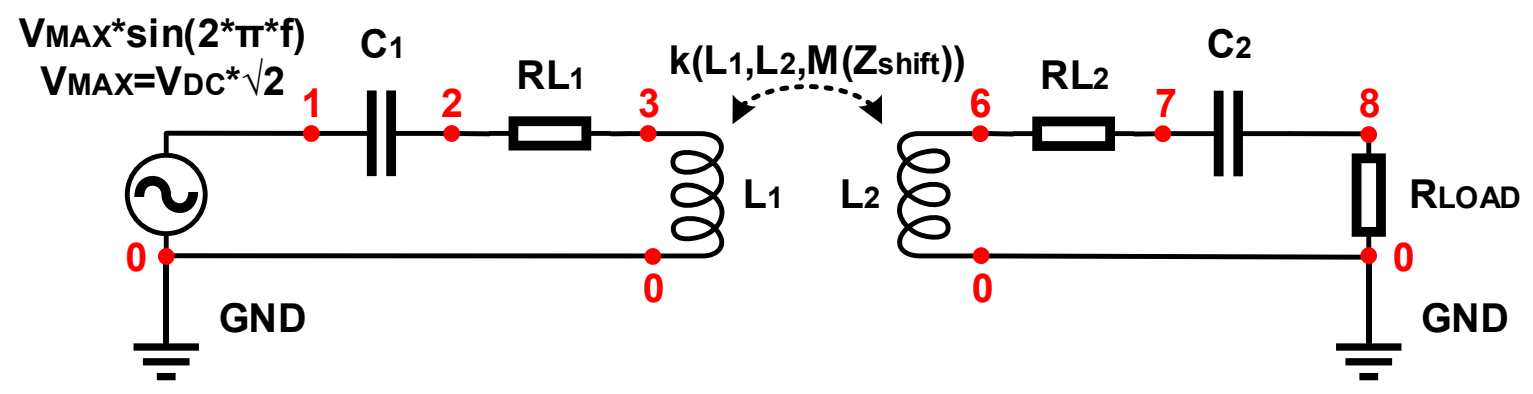

Figure 6. Electrical circuit definition within simulation model. 
Table 4. Electrical circuit settings.

\begin{tabular}{|c|c|c|c|}
\hline Circuit Element & Value & Point (+) & Point (-) \\
\hline Ground & GND & 0 & 0 \\
\hline Voltage source & $\mathrm{V}_{\mathrm{MAX}} \times \sin (\omega \mathrm{t})$ & 0 & 1 \\
\hline Capacitor 1 & 1/( $\omega^{2 *}$ comp1.mf.LCoil_1) [F] & 1 & 2 \\
\hline Resistor 1 & $\mathrm{R}_{\text {Coil1 }}[\Omega]$ & 2 & 3 \\
\hline External I vs. U1 & Coil voltage (mf3/coil1) & 3 & 0 \\
\hline External I vs. U2 & Coil voltage (mf3/coil2) & 0 & 6 \\
\hline Resistor 2 & $\mathrm{R}_{\text {Coil2 }}[\Omega]$ & 6 & 7 \\
\hline Capacitor 2 & 1/( $\omega^{2 *}$ comp2.mf2.LCoil_1) [F] & 7 & 8 \\
\hline Load & $\mathrm{R}_{\mathrm{LOAD}}[\Omega]$ & 8 & 0 \\
\hline
\end{tabular}

For further evaluation of the in the loop model's accuracy, the measurement and simulation experiment was realized considering the power transfer within the distance of $206 \mathrm{~mm}$. The amplitude of input voltage was set to $325 \mathrm{~V}$ and the value of the load was $11.9 \Omega$. These parameters settings are valid for both shielded and non-shielded WPT system. As can be seen from comparisons of the measurement and simulation (Figures 7 and 8), the transfer characteristics relevant for the simulation model reflects the shape and values to those received from experimental measurement. If non-shielded system is under consideration, the average accuracy of the proposed model is more than $95 \%$. In the case of the shielded system the accuracy of the proposed model is higher than 96\% (Figure 8.)

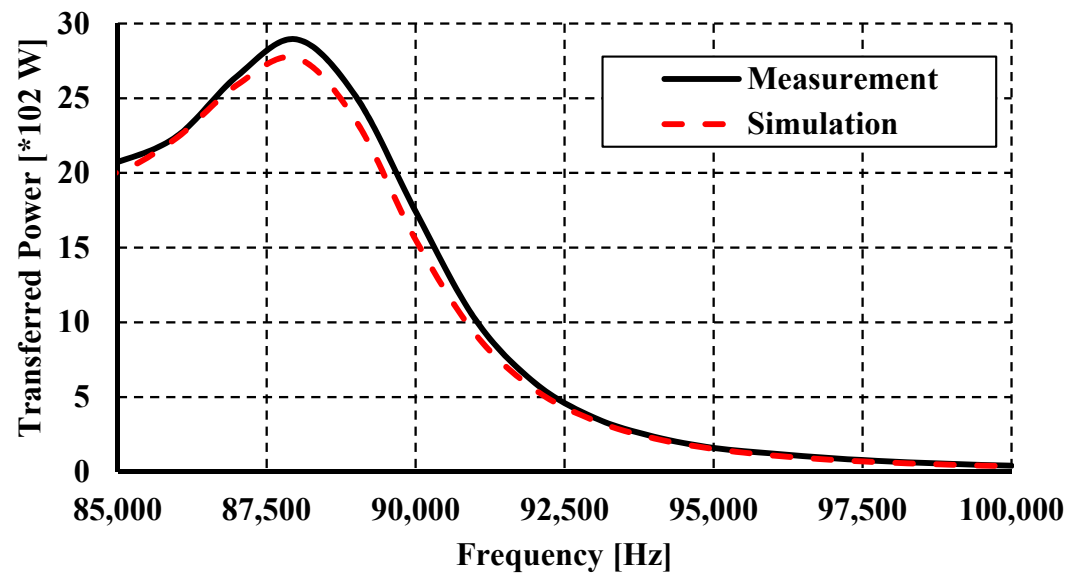

Figure 7. Model verification-Transferred power dependency on frequency (Non-shielded system).

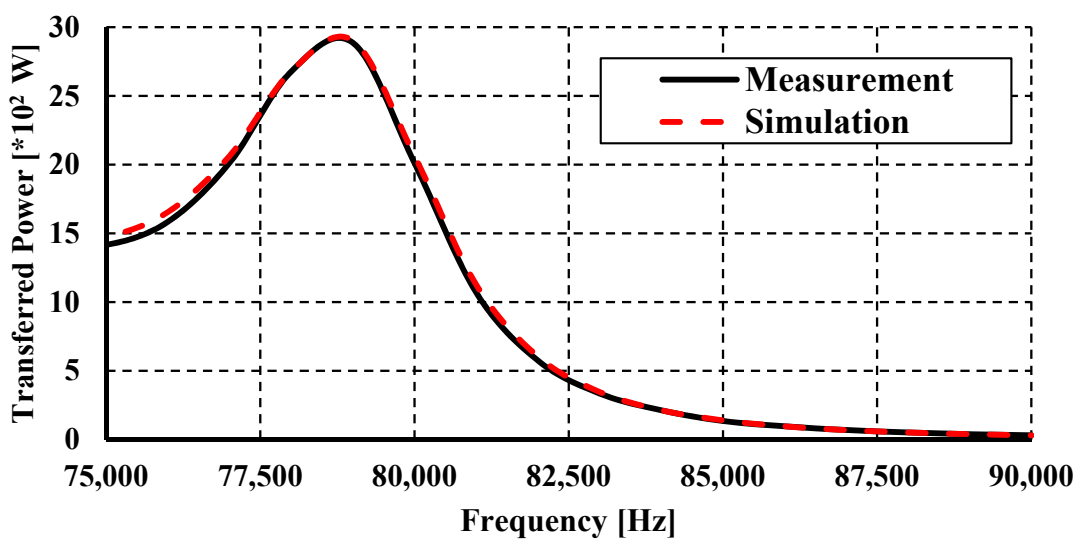

Figure 8. Model verification-Transferred power dependency on frequency (System with magnetic shielding). 
The last part of the model verification is focused on the evaluation of electro-magnetic field intensity at 3 different distances from the receiving coil. Receiving coil is located at the top part of proposed WChS, while measuring coil is placed as shown on Figure 8 right. In order to identify magnitudes of the radiated field within z-axe, the measurement of the induced voltage was performed with the use of measuring coil (Figure 9 left). Measuring coil is made of the same litz wire as in the case of the coils for the WChS, while the diameter of the coil is 100 [mm].

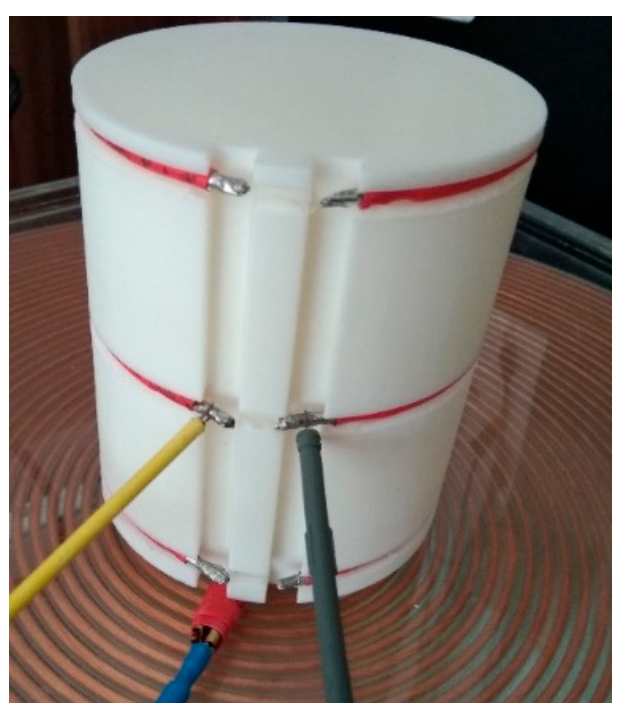

(a)

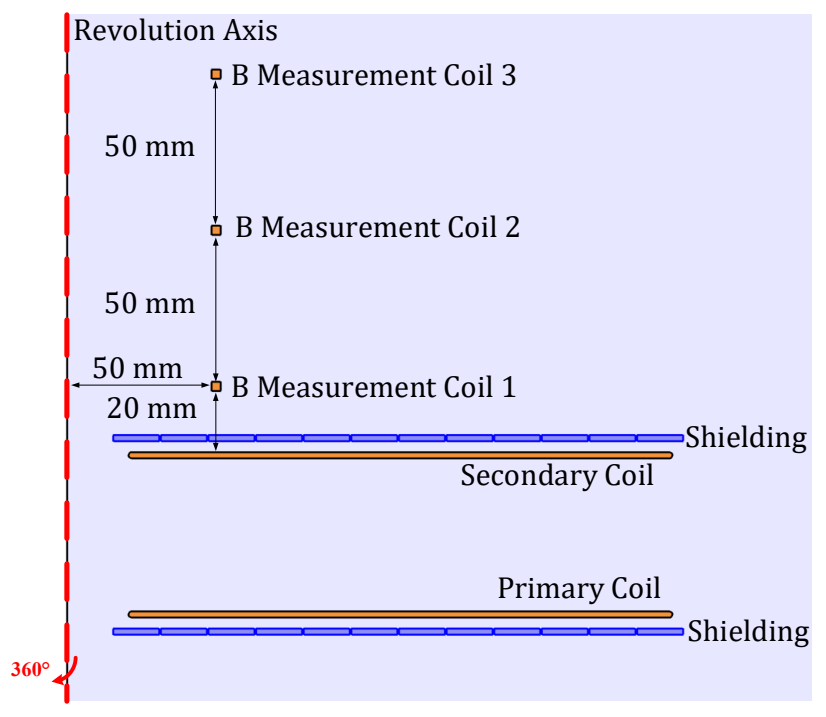

(b)

Figure 9. Measuring Coil for electromagnetic (EM) Field Radiation (a) and description of physical arrangement during measurement (b).

Once again, the comparisons have been provided analyzing the values of the inducted voltage in dependency on operating frequency of WChS, while detection point was selected as $20 \mathrm{~mm}$ from the top of receiving coil. Amplitude of input voltage for this verification is set to $325 \mathrm{~V}$ and the load is $11.9 \Omega$ as in previous experiments. As can be seen at Figure 10 (Non-Shielded situation) and Figure 11 (Shielded situation), the relative error of the results between measurement and simulation model is for both cases less than $3 \%$.

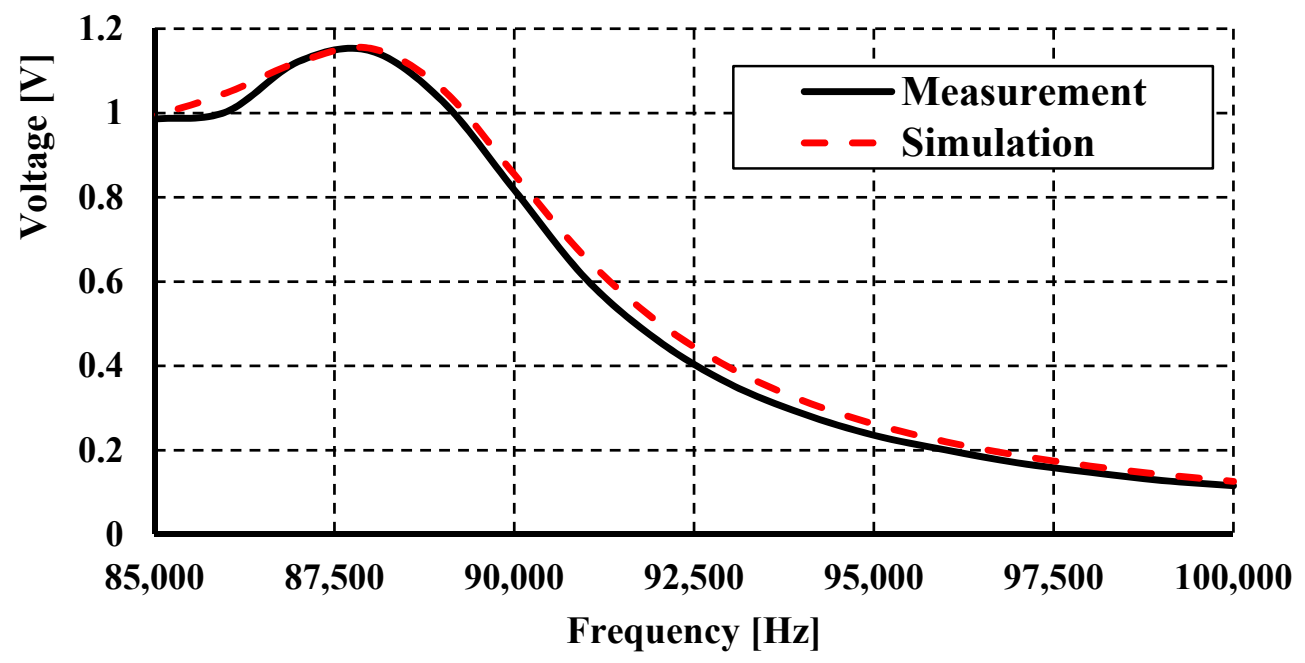

Figure 10. EM radiation verification-induced voltage level on measuring coil at $20 \mathrm{~mm}$ distance (Non-Shielded wireless power transfer (WPT) system). 


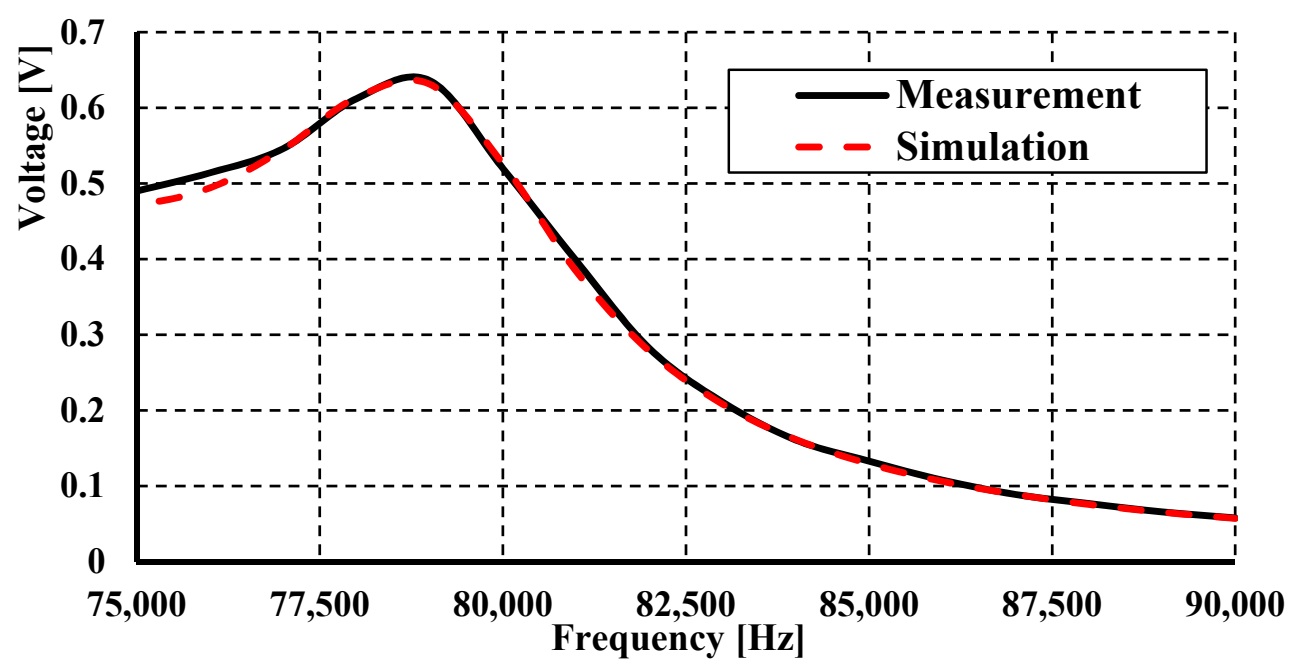

Figure 11. EM radiation verification-induced voltage level on measuring coil at $20 \mathrm{~mm}$ distance (Shielded WPT system).

Previous analyses showed that individual calculation stages of the designed simulation models achieved accuracy within the range of $93 \%-97 \%$ as shown in Table 5.

Table 5. Maximal relative error of the proposed models in given frequency range.

\begin{tabular}{ccccc}
\hline & \multicolumn{2}{c}{ Transferred Power [W] } & \multicolumn{2}{c}{ EM Field Induced Voltage [V] } \\
\cline { 2 - 5 } & $\begin{array}{c}\text { Non-Shielded } \\
\text { System }\end{array}$ & $\begin{array}{c}\text { Shielded } \\
\text { System }\end{array}$ & $\begin{array}{c}\text { Non-Shielded } \\
\text { System }\end{array}$ & $\begin{array}{c}\text { Shielded } \\
\text { System }\end{array}$ \\
\hline Measurement & 2350 & 1416 & 0.61 & 0.51 \\
\hline Simulation & 2510 & 1510 & 0.65 & 0.49 \\
\hline Error [\%] & 6.80 & 6.51 & 6.56 & -3.92 \\
\hline
\end{tabular}

\section{User Guided in Loop Design of Wireless Power Transfer System}

Based on the previous evaluations it can be said that the proposed models are accurate and can be used for optimization of the WChS and its electromagnetic shielding. All the listed Equations (1)-(22) together with previously described and verified models are used within developed User guided in loop design, which is described below.

Figure 12 shows first initialization part of developed UI. It serves for determination of all required variables for determination of consequent parameters needed for calculations. These main input parameters are as follows: output power at secondary side of WChS, expected nominal load, requirement on outer diameter of the coil, transfer distance, efficiency of coil to coil power transfer and the value of operating frequency. Based on these input definitions, the geometrical properties of the coils are being calculated together with information about minimal input voltage of the system, which is required to reach nominal output power.

The calculation of the parameters given by (1)-(11) is provided in the loop, while during each calculation step, the length of the wire is incremented for given turn of the coil (8) with defined radial distance between the turns. In the case that inner diameter of the coil decreases below $10 \mathrm{~mm}$ and required length of the wire is not achieved, whole calculation process is repeated while two parallel strands are consequently considered. In this way, the diameter of the wire is reduced together with radial distance between turns. The maximum number of parallel strands is set to 5 . Even for 5 parallel strands the value of required length of the coil's wire is not determined, the UI will I inform the user to increase the value of outer diameter of the coil. 


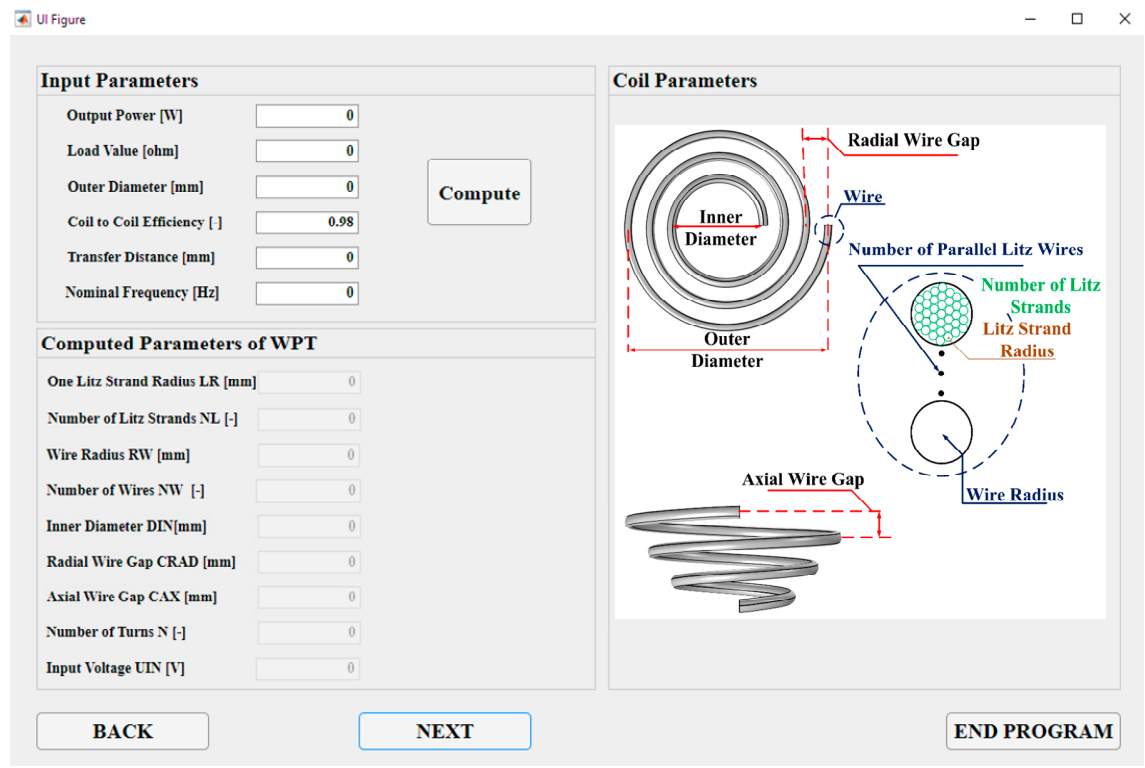

Figure 12. Display showing input parameters definition regarding application purposes (top-left part) and display showing calculated parameters of the coil (bottom-left part).

Within next in the loop design step (Figure 13) it is possible to implement the results from previous calculation steps, while if required it is possible to define those parameters themselves. For both cases it is then necessary to "rewrite parameters" (Figure 13) to store variables for next calculation purposes. Within this design step it is also possible to define the material properties of the coil's wire, while pre-defined setting is copper material. Similar procedure is then required for the secondary side coil.

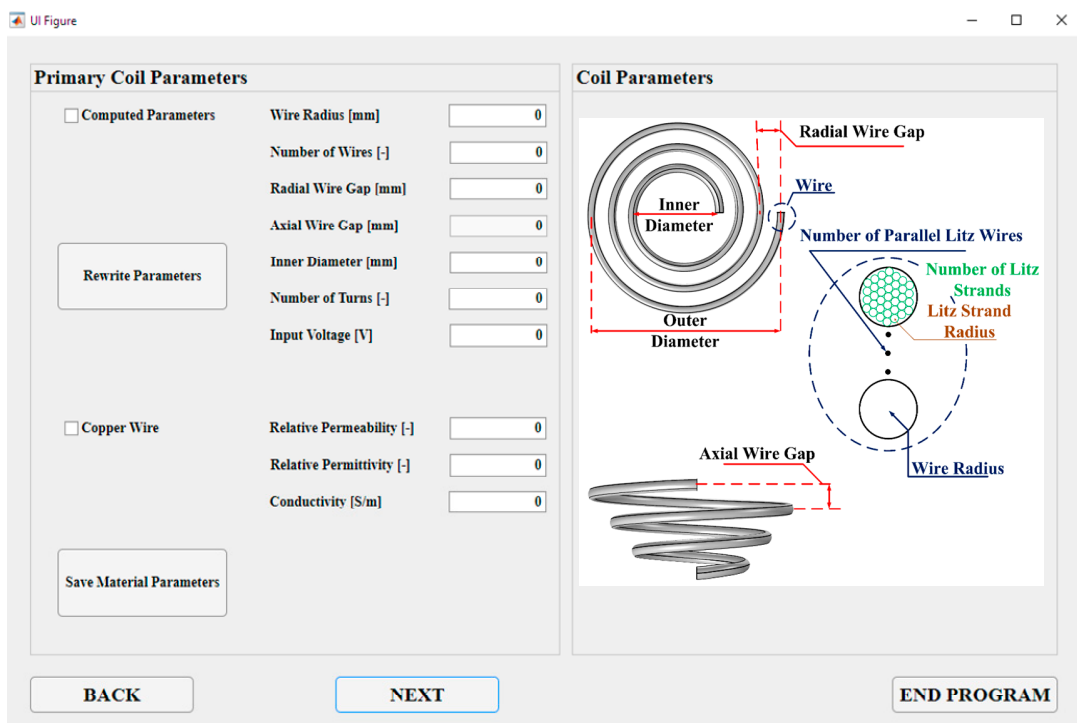

Figure 13. Display showing geometrical parameters definition (top-left part) and display showing material parameters definition (bottom-left part).

After the step, which is relevant for geometrical design of the coils, user receives results for the non-shielded WChS. To be able to optimize material and geometrical parameters of shielding system (magnetic as well as electric) next step is given for definition of requirements on the primary coil shielding components. Figure 14 shows that it is possible to check which type of shielding is going to be used. After selection, it is possible to define required shape, that is, fully shielded system (full plate), inner wall or outer wall what is related to inner and outer parts of the coil or finally it is possible to 
use partially shielded system based on the consideration of ferrite rings. If the specification of the shielding shape is done, then it is possible to define required parameters of the shielding system, that is, Magnetic Shielding Thickness, Coil Shielding Gap, External Diameter, Ring Width, Number of Rings or Gap Between Rings. In this step the range of values can be given for thickness and the distance from coil for both parts of the shielding. Together with these specifications, material properties are required like relative permeability, relative permittivity and conductivity of shielding material. Consequently, similar process is required for secondary side coil. Here the possibility to select similar configuration is available "Primary Coil Equivalent." Next step of proposed design procedure is simulation, while during this step each of previously described FEM models are created together with their solution. Final step is postprocessing of the results, whereby considering distribution of electromagnetic field within WChS surrounding both non-shielded and shielded systems are displayed. In case of the user defined range of values, the displayed results are for the last combination of the values combination, while all other combinations are stored within working folder. The user is then able to move the simulation range in the desired direction based on the set of results.

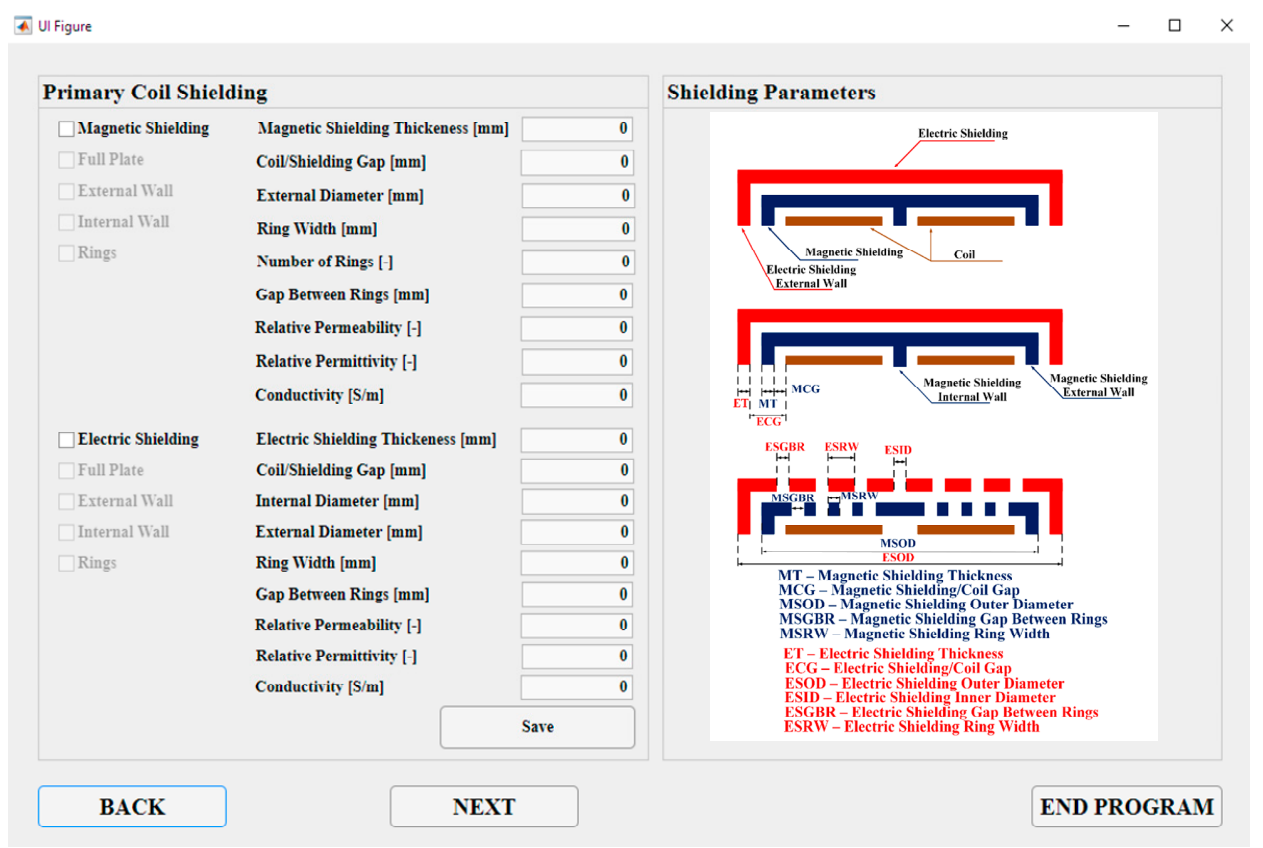

Figure 14. Display showing magnetic shielding parameters definition (top-left part) and display showing electric shielding parameters definition (bottom—left part).

All models created for the calculation of required parameters are stored in the application folder and can be used outside the UI. Thus, the created UI can also serve as optimization tool for design of a reconfigurable model. With the use of such approach it is subsequently possible to investigate the influence of a larger number of parameters than this interface allows.

\section{Evaluation of Proposed Modeling Approach with WChS Suited for Automotive Charging}

At this point the use of designed user guide will be verified through the experimentation on the physical prototype of wireless charger for automotive application operated at nominal conditions. The main input to output specifications are as follows:

- $\quad$ Input Voltage $=$ rectified 3-phase $(3 \times 230 \mathrm{Vac})$ voltage, $\mathrm{V}_{\mathrm{INDC}}=$ app. $570 \mathrm{~V}$

- $\quad$ Operating frequency $=85 \mathrm{kHz}$

- $\quad$ Peak output power $=9 \mathrm{~kW}$, nominal power $=7 \mathrm{~kW}$ 
Main aim of experimentation is to optimize EM field distribution for proposed WChS using presented in loop design user guide. The specifications related to the coils design have been considering above mentioned input/output parameters. Initially, the simulation analysis of the magnetic field distribution was done for the non-shielded system (Figure 15). From results it is seen, where the effective value of magnetic induction reaches limiting field level defined by ICNIRP 2010 for public exposure [20-22]. It is highlighted by the white dashed lines for vertical and horizontal plane.

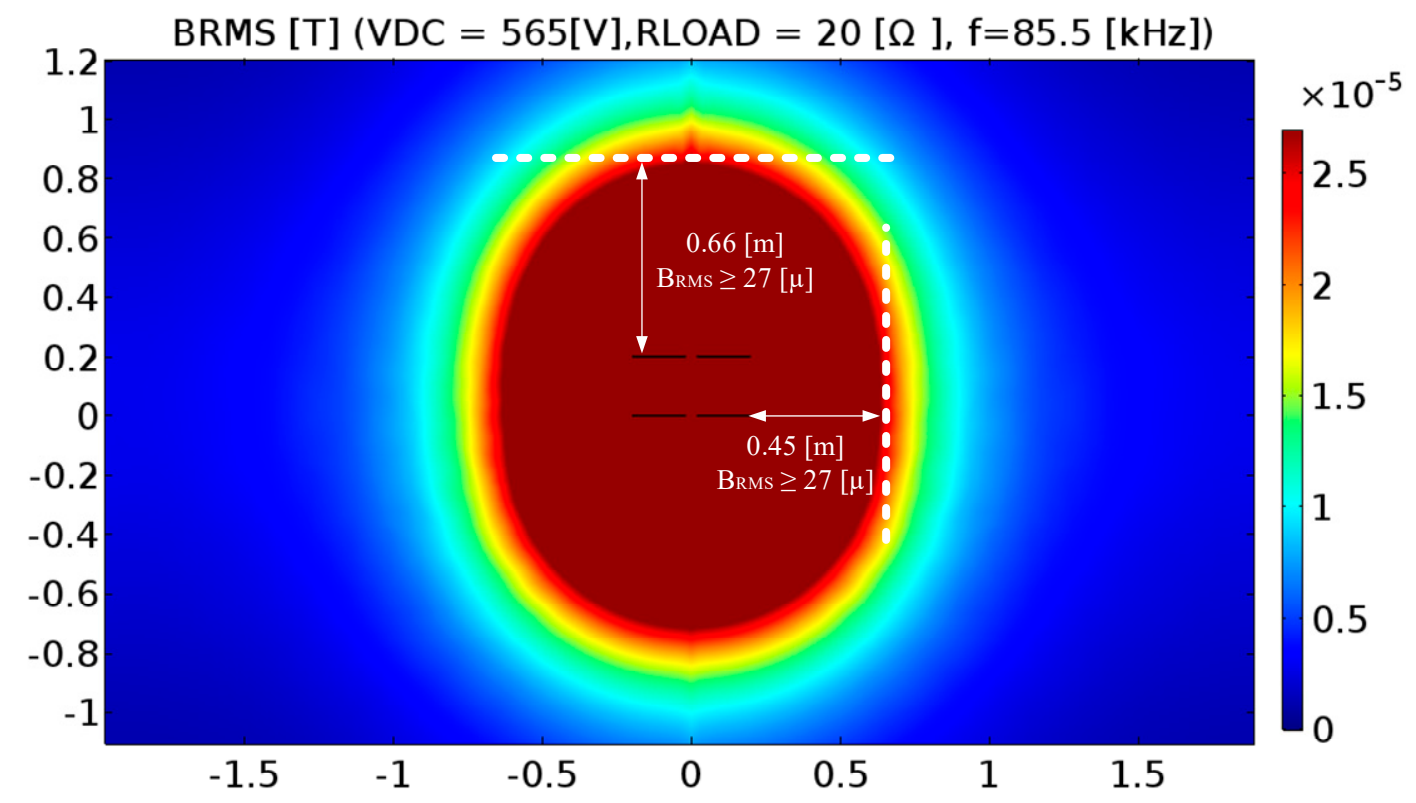

Figure 15. The distribution of the magnetic flux density of the Non-Shielded WChS.

The achieved results present enormous magnetic intensity exposure for relatively far distance if practical use and long-term charging is considered. Therefore, the application of the shielding system was defined within user guide environment (Figure 14). For transmitting (bottom) coil the partially shielded (rings) system was used, while for receiving coil fully shielded system was utilized. The material properties and geometric arrangement of used ferrite bricks are made of N92 ferrite material with dimensions of $25 \mathrm{~mm} \times 14 \mathrm{~mm} \times 2.5 \mathrm{~mm}$.

The results from simulation analysis of the magnetic field distribution for shielded WChS is shown on Figure 16. Here it is seen that significant reduction of the effective value of magnetic intensity is reached within vertical direction. Compared to non-shielded system, the limiting field level was reduced from $66 \mathrm{~cm}$ to $25 \mathrm{~cm}$. From practical point of view, it is acceptable results if other construction properties of charged system are considered (location of receiving coil within car chassis). Horizontal reduction is also evident, while limiting area was reduced by $10 \mathrm{~cm}$. So here it can be said that optimization purposes of the EM radiation of WChS can be easily done with the use of proposed in loop design methodology.

Achieved simulation results have been verified by the similar experimental measurement of the EM field distribution. Graphical interpretation of the experimental measurement set-up is being shown on Figure 17. Input voltage is supplied by DC input source (Magna-Power TS 600). It is directly connected to primary side $\mathrm{SiC}$ full-bridge inverter. In order to meet good operational properties and to reduce the complexity of control, the output rectifier is based on SiC bridge technology supplying programable electronic load (EA-EL 9400-100). If target application is considered, it is then expected to use secondary side converter in order to regulate voltage and current required by the application. 


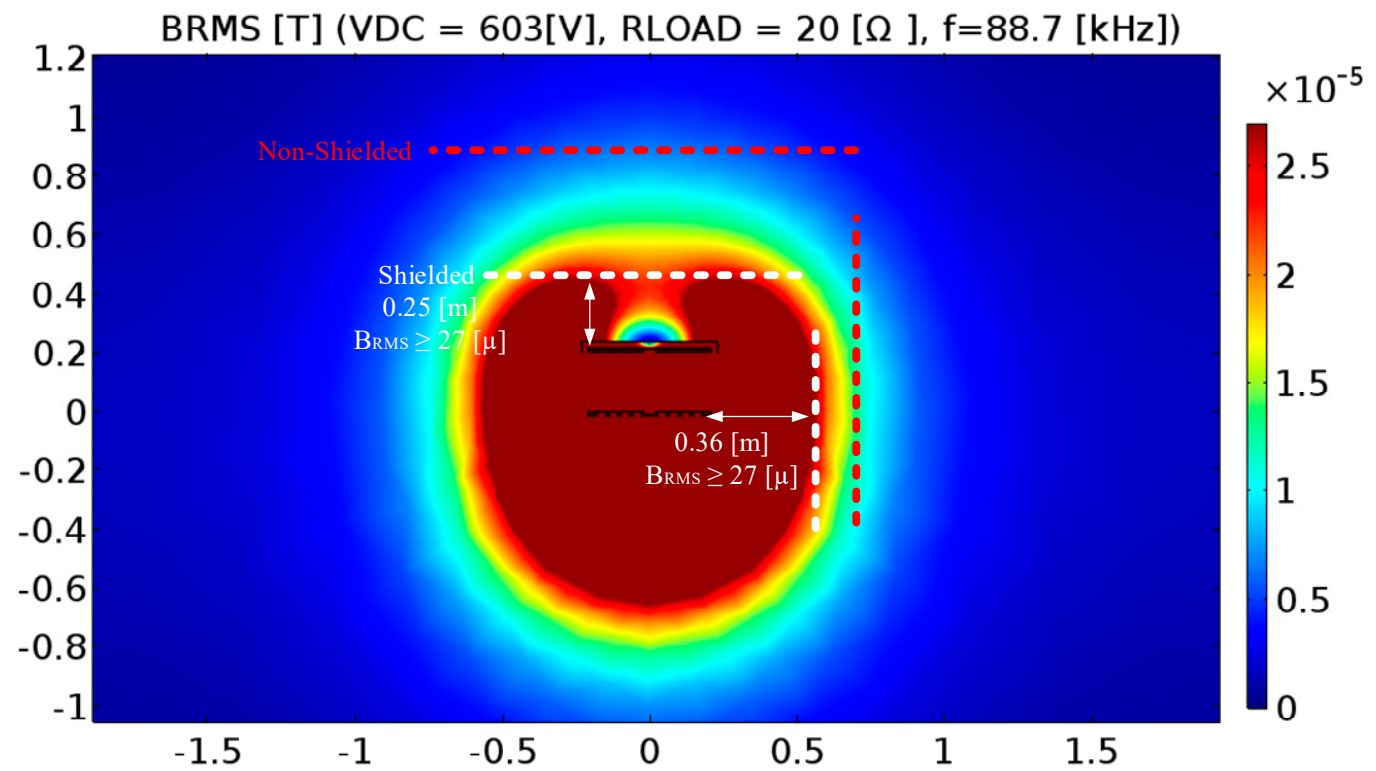

Figure 16. The distribution of the magnetic flux density of the Shielded WChS (white lines), Non-Shielded WChS (Red Lines).

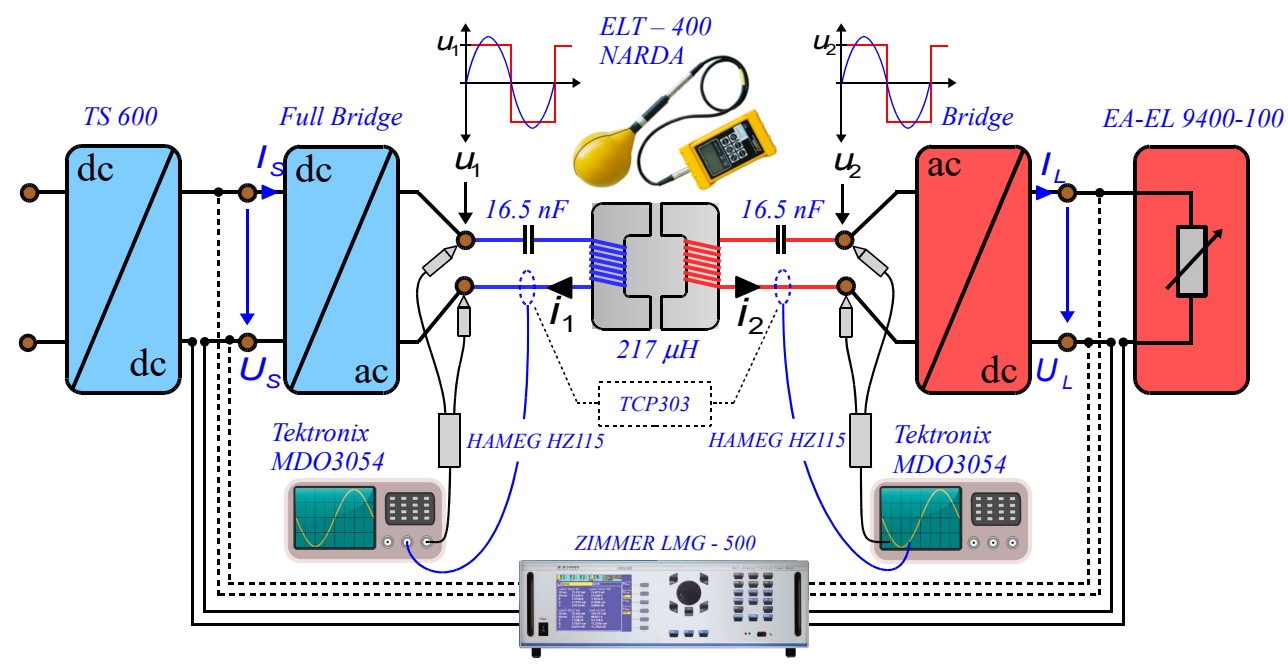

Figure 17. Graphical interpretation of experimental measurement set-up.

Experimental measurement using laboratory test stand was focused on the determination of the electromagnetic field distribution around the WChS. The leakage magnetic field distribution was analyzed within the defined plane (as for simulation), which was array in the cutting plane with $180 \mathrm{~cm} \times 180 \mathrm{~cm}$ dimensions. This approach is based on the regulations given by international standards ICNIRP. Received results from experimental measurement are represented on Figure 18.

From the experimental results is seen (Figure 8) that the field distribution is like the one received from simulation analysis. If focus is given on the limiting areas, the experiment shows that effective value of $27 \mu \mathrm{T}$ is located at around $28 \mathrm{~cm}$ from receiving coil (distance is measured at the top of the coil excluding magnetic shielding). Within horizontal plane, limiting threshold is achieved at the $36 \mathrm{~cm}$ from the side of the coil. Both results confirm very high accuracy and reliability of the proposed in loop design methodology and simulation model as well. 


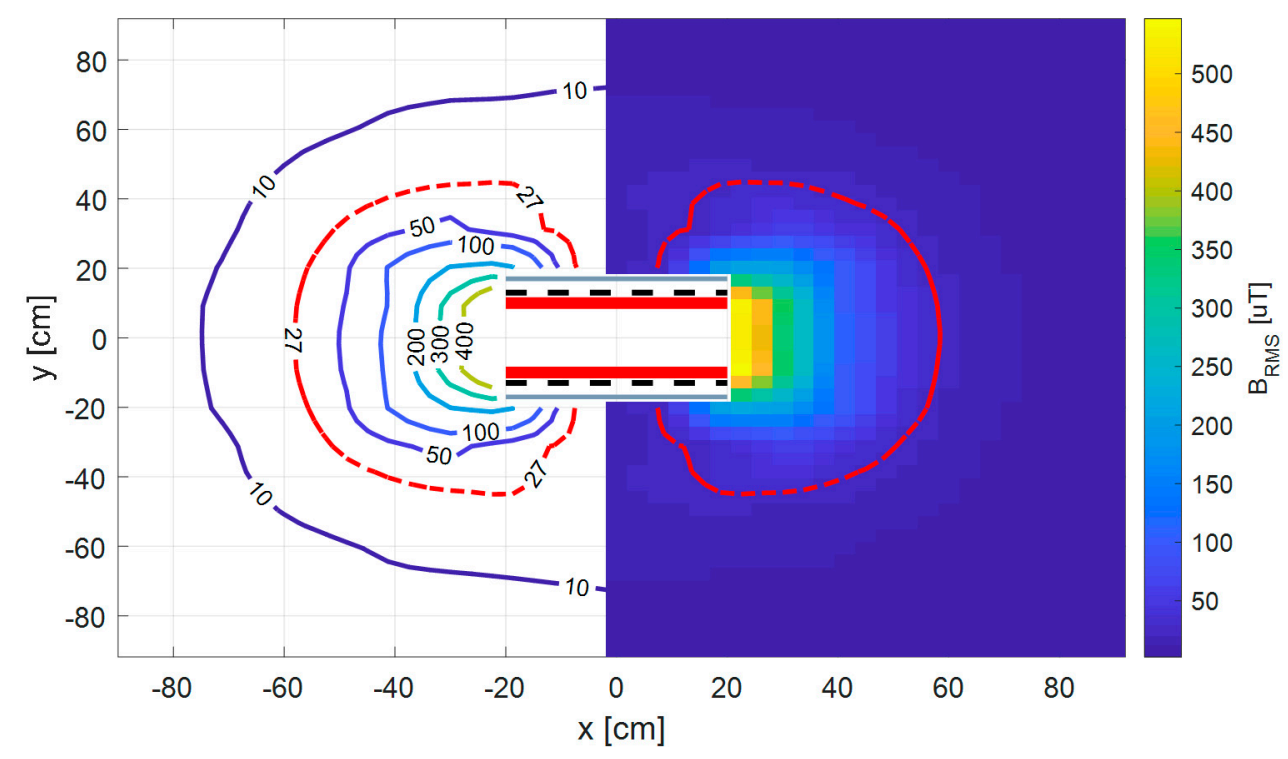

Figure 18. Magnetic field distribution around system of coils of experimental WChS prototype.

\section{Conclusions}

The paper has given possibility for optimized design of the coupling coils suited for the wireless power charging. The proposal is based on the use of calculation procedure for geometric shape and dimensions of the coils. Consequently, highly accurate and validated finite-element simulation models are implemented within the design procedure. Initially, the evaluation of the individual finite element sub-models was validated through the characteristics and main parameters comparisons. It was discovered that individual parts of simulation models are exhibiting high accuracy maintained within range of $95 \%-98 \%$. The secondary part of the simulation model and user guide environment enables to define magnetic and electric shielding system, while various geometrical modification of magnetic shield can be applied. The EM field distribution analysis around WChS is then possible, moreover optimization of the geometrical as well as material properties is possible to meet required limits defined by international standards. In order to validate simulation methodology and in loop design approach, the physical prototype of proposed wireless power charging system was designed. For coil geometry and parameters identification the in-loop design procedure was utilized, while input and output parameters were related to automotive power charging. The evaluation of the simulation model was performed in the way of identification of magnetic field distribution. For this purpose, experimental prototype was analyzed for defined conditions. After comparisons of the simulation and experimental results, it was confirmed that proposed in loop design and simulation models are provided highly accurate results almost for the EM field distribution. Thus, it can be concluded here, that using proposed approach it is possible to achieve rapid optimization of key properties of wireless power charging systems.

Author Contributions: M.P. was responsible for definitions of design methodology, modeling—simulationvalidation and original paper writing. M.F. is responsible for formal analysis and original paper preparations. All authors have read and agreed to the published version of the manuscript.

Funding: This publication was realized with support of Operational Program Integrated Infrastructure 2014-2020 of the project: Innovative Solutions for Propulsion, Power and Safety Components of Transport Vehicles, code ITMS 313011V334, co-financed by the European Regional Development Fund. Authors would like to thank also to national grant agency APVV for project funding APVV-0345-17.

Conflicts of Interest: The authors declare no conflict of interest. 


\section{References}

1. Melki, R.; Moslem, B. Optimizing the design parameters of a wireless power transfer system for maximizing power transfer efficiency: A simulation study. In Proceedings of the 2015 Third International Conference on Technological Advances in Electrical, Electronics and Computer Engineering (TAEECE), Beirut, Lebanon, 29 April-1 May 2015; pp. 278-282. [CrossRef]

2. Hadadtehrani, P.; Dehghani, S.; Molavi, R.; Janarthanan, V.; Johnson, T.; Mirabbasi, S. Analysis, design, and characterization of wireless power transfer systems using conical coils. In Proceedings of the 2016 14th IEEE International New Circuits and Systems Conference (NEWCAS), Vancouver, BC, Canada, 26-29 June 2016; pp. 1-4. [CrossRef]

3. Tang, Y.; Ma, H.; Thrimawithana, D.J.; Madawala, U.K. Copper foil windings for WPT systems. In Proceedings of the 2017 IEEE PELS Workshop on Emerging Technologies: Wireless Power Transfer (WoW), Chongqing, China, 20-22 May 2017; pp. 162-167. [CrossRef]

4. Pratik, U.; Varghese, B.; Azad, A.N.; Pantic, Z. Optimum Design of Decoupled Concentric Coils for Operation in Double-Receiver Wireless Power Transfer Systems. IEEE J. Emerg. Sel. Top. Power Electron. 2018, 7, 1982-1998. [CrossRef]

5. Castillo-Zamora, I.U.; Huynh, P.S.; Vincent, D.; Perez-Pinal, F.J.; Rodriguez-Licea, M.A.; Williamson, S.S. Hexagonal Geometry Coil for a WPT High-Power Fast Charging Application. IEEE Trans. Transp. Electrif. 2019, 5, 946-956. [CrossRef]

6. Kindl, V.; Zavrel, M.; Drabek, P.; Kavalir, T. High Efficiency and Power Tracking Method for Wireless Charging System Based on Phase-Shift Control. Energies 2018, 11, 2065. [CrossRef]

7. Zeng, H.; Yang, S.; Peng, F.Z. Design Consideration and Comparison of Wireless Power Transfer via Harmonic Current for PHEV and EV Wireless Charging. IEEE Trans. Power Electron. 2016, 32, 5943-5952. [CrossRef]

8. Zhou, Z.; Li, W.; Cheng, C.; Wang, C.; Deng, Z.; Mi, C. A Wireless Power Transfer System Powering Multiple Gate Drivers in a Modular Multilevel Converter. In Proceedings of the 2019 IEEE PELS Workshop on Emerging Technologies: Wireless Power Transfer (WoW), London, UK, 18-21 June 2019; pp. 401-405. [CrossRef]

9. Ahmad, A.; Alam, M.S.; Chabaan, R. A Comprehensive Review of Wireless Charging Technologies for Electric Vehicles. IEEE Trans. Transp. Electrif. 2018, 4, 38-63. [CrossRef]

10. Zhu, Q.; Zhang, Y.; Guo, Y.; Liao, C.; Wang, L.; Wang, L. Null-Coupled Electromagnetic Field Cancelling Coil for Wireless Power Transfer System. IEEE Trans. Transp. Electrif. 2016, 3, 1. [CrossRef]

11. Sirbu, I.-G.; Mandache, L. Comparative analysis of different topologies for wireless power transfer systems. In Proceedings of the 2017 IEEE International Conference on Environment and Electrical Engineering and and Commercial Power Systems Europe (EEEIC/I\&CPS Europe), Milan, Italy, 6-9 June 2017; pp. 1-6. [CrossRef]

12. Spanik, P.; Frivaldsky, M.; Piri, M.; Kindl, V. Wireless power transfer system with reduced voltage stress on compensation capacitors. In Proceedings of the IECON 2016-42nd Annual Conference of the IEEE Industrial Electronics Society, Florence, Italy, 23-26 October 2016; pp. 1190-1195. [CrossRef]

13. Lu, F.; Zhang, H.; Hofmann, H.F.; Mi, C. An Inductive and Capacitive Combined Wireless Power Transfer System With LC-Compensated Topology. IEEE Trans. Power Electron. 2016, 31, 8471-8482. [CrossRef]

14. Chen, R.; Zheng, C.; Zahid, Z.U.; Faraci, E.; Yu, W.; Lai, J.-S.; Senesky, M.; Anderson, D.; Lisi, G. Analysis and parameters optimization of a contactless IPT system for EV charger. In Proceedings of the 2014 IEEE Applied Power Electronics Conference and Exposition-APEC, Fort Worth, TX, USA, 16-20 March 2014; pp. 1654-1661. [CrossRef]

15. Kim, H.; Song, C.; Kim, D.-H.; Jung, D.H.; Kim, I.-M.; Kim, Y.-I.; Kim, J.; Ahn, S.; Kim, J. Coil Design and Measurements of Automotive Magnetic Resonant Wireless Charging System for High-Efficiency and Low Magnetic Field Leakage. IEEE Trans. Microw. Theory Tech. 2016, 64, 1-18. [CrossRef]

16. Patil, D.; McDonough, M.K.; Miller, J.M.; Fahimi, B.; Balsara, P.T. Wireless Power Transfer for Vehicular Applications: Overview and Challenges. IEEE Trans. Transp. Electrif. 2017, 4, 3-37. [CrossRef]

17. Kim, J.; Kim, H.; Song, C.; Kim, I.-M.; Kim, Y.-I.; Kim, J. Electromagnetic interference and radiation from wireless power transfer systems. In Proceedings of the 2014 IEEE International Symposium on Electromagnetic Compatibility (EMC), Raleigh, NC, USA, 4-8 August 2014; pp. 171-176. [CrossRef] 
18. Iwamoto, T.; Arima, T.; Uno, T.; Wake, K.; Fujii, K.; Watanabe, S. Measurement of electromagnetic field in the vicinity of wireless power transfer system for evaluation of human-body exposure. In Proceedings of the 2014 International Symposium on Electromagnetic Compatibility, Tokyo, Japan, 12-16 May 2014; pp. 529-532.

19. Chakarothai, J.; Wake, K.; Arima, T.; Watanabe, S.; Uno, T. Exposure Evaluation of an Actual Wireless Power Transfer System for an Electric Vehicle with Near-Field Measurement. IEEE Trans. Microw. Theory Tech. 2017, 66, 1543-1552. [CrossRef]

20. Kim, J.; Kim, J.J.; Kong, S.; Kim, H.; Suh, I.-S.; Suh, N.P.; Cho, D.-H.; Kim, J.; Ahn, S. Coil Design and Shielding Methods for a Magnetic Resonant Wireless Power Transfer System. Proc. IEEE 2013, 101, 1332-1342. [CrossRef]

21. Zhang, W.; Mi, C.C. Compensation Topologies of High-Power Wireless Power Transfer Systems. IEEE Trans. Veh. Technol. 2016, 65, 4768-4778. [CrossRef]

22. ICNIRP2010. International Commission on Non-Ionizing Radiation Protection. 2010. Available online: http://www.icnirp.org/cms/upload/publications/ICNIRPLFgdl.pdf (accessed on 7 August 2018).

Publisher's Note: MDPI stays neutral with regard to jurisdictional claims in published maps and institutional affiliations.

(C) 2020 by the authors. Licensee MDPI, Basel, Switzerland. This article is an open access article distributed under the terms and conditions of the Creative Commons Attribution (CC BY) license (http://creativecommons.org/licenses/by/4.0/). 